\title{
Psychological Risk Factors of Future Drug Offending among Young Offenders in Hong Kong - A Longitudinal Study
}

\author{
Elise S. W. Hung ${ }^{1}$ \\ ${ }^{1}$ Hong Kong Correctional Services, Hong Kong \\ Correspondence: Elise S. W. Hung, Hong Kong Correctional Services, Hong Kong.
}

Received: October 16, 2020

Accepted: November 19, 2020

Online Published: November 26, 2020

doi:10.5539/ijps.v12n4p31

URL: https://doi.org/10.5539/ijps.v12n4p31

\begin{abstract}
In recent years there is a growing concern on drug offenders in Hong Kong. Despite its over-representation in prison and recidivists, drug offending has seldom been studied systematically in risk factor research. The issue as to whether drug offending has specific psychological risk factors or they share a common set of risk factors with general offending remains largely unaddressed. This research applied a longitudinal design to investigate this issue. Using a data-set on young offenders' psychological characteristics established in 2004 in the Hong Kong Correctional Services, and re-conviction data retrieved 11 years later in 2015, ANCOVA with planned orthogonal contrasts and Discriminant Function Analysis, Correlation and Regression analyses were used to analyze factors predicting post-release outcomes including recidivism, drug offending, and crime severity. Results revealed two sets of psychological risk factors with little overlap that could predict general recidivism (of all types of crime) and future drug offending. Recidivism could be predicted by low Future Time Perspective and Empathy, and high Assertiveness. Low Empathy was predictive of post-release crime severity of non-drug offending recidivists. Drug offending, in contrast, could be predicted by high Impulsiveness and Social Problem-solving deficits during adolescence. These two variables, together with low Assertiveness, also predicted post-release crime severity of drug-offending recidivists. Implications to future intervention and research were discussed.
\end{abstract}

Keywords: drug offending, psychological risk factors, young offenders, recidivism

\section{Introduction}

According to the World Health Organization (2020), an estimate of 275 million people used illicit drugs, such as cannabis, amphetamines, and cocaine, and some 31 million of people who use drugs suffer from drug use disorders. According to the National Survey on Drug Use and Health, 19.7 millions American adults and approximately 4\% (i.e. 992000 ) of the American adolescent population aged 12 to 17 suffered from a substance use disorder in 2017 (Substance Abuse and Mental Health Services Administration, 2018). Drug-involved individuals are also statistically shown to be over-represented in the offender population in Hong Kong. Based on records of the Hong Kong Correctional Services (HKCS) (2018), 80 percent of prisoners in high-security institutions in 2017 had committed serious drug offences directly related to drugs. Ex-prisoners placed under statutory post-release supervision were recalled to prisons mainly because of drug abuse during the supervision period (Audit Commission of Hong Kong, 2015).

Drug abuse is seldom discussed in isolation from drug offending, which refers to the "possession, use, sale or furnishing of any drug or intoxicating substance or drug paraphernalia that is prohibited by law" (USLegal, 2019). Drug offending is an alarming type of specific offending because increased drug use was associated with increased drug availability (National Drug Intelligence Center, 2011). In the process of drug consumption, drug offending such as processing, manufacturing and selling drugs, has a crucial role in sustaining habitual drug use and causing drug addiction. Among all age groups, illicit drugs act in a more potent way on adolescents than adults (Prichard \& Payne, 2005). Comorbid offending and substance misuse in delinquents engaged in more subsequent crime and experienced more social problems and addiction symptoms than those who merely offended (Walters, 2014). More importantly, chronic drug use can cause brain changes leading to inability to resist drugs and inhibit further offending (Grant \& Chamberlain, 2014). Nevertheless, drug offenders were seldom studied as systematically as other specific offenders like sexual and violent offenders, for whom risk assessment tools had been well developed and validated.

The present study attempts to deepen our understanding of the psychological risk factors of drug offending 
among a high-risk population, i.e. young offenders, in Hong Kong, within the context of adolescent offending and re-offending. The issue as to whether some well-known variables constitute common risk factors to both general and drug offending among youngsters, or in fact drug offending can be predicted by specific risk factors, has not been systematically addressed in prior research. This study was an attempt to fill this research gap.

\subsection{Literature Review}

\subsubsection{Theoretical Paradigms}

This research was guided by two highly relevant theoretical paradigms of the psychology of offending: the diathesis-stress theory (DST) (Eysenck, 1987; Belsky \& Pluess, 2009) and the externalization spectrum conceptualization (ESC) (Kruegar et al., 2005; 2007).

The DST postulates a predisposition to develop certain types of mental or behavioral disorder activated by certain environmental stress factors. It postulates that a general vulnerability to offending is formed by a combination of many individual vulnerability or psychological risk factors, such as cognitive and behavioral skill deficits, emotion dysregulation, and cognitions. The more vulnerable individuals possessing a greater number of risk factors commit offences upon triggers by less intense stressors, such as a high-stress family environment (Marshall, Anderson, \& Fernandez, 1999). Once the pertinent risk factors have been identified, intervention could be directed at them in members of a problematic segment of the adjudicated delinquent population that tend to persist in crime beyond adolescence (Walters, 2015). Besides, as the risk factors that it addresses can exert distal influences and have limited variability without target-specific intervention, extreme scores on those factors may account for the etiology of criminal behavior in specific circumstances. Identifying risk factors that differentiate offenders from non-offenders are promising tools for assessing offenders' risk for offending (Leue, Brocke, \& Hoyer, 2008). This research is an attempt to identify risk factors of drug offending through differentiation of drug offenders from other non-drug offenders.

The ESC emphasizes on a coherent and genetically-based liability dimension causing an individual to act in an unconstrained manner towards "externalizing" or acting out. It posits that impulsiveness and aggressiveness, the "big two", are the "most relevant specific traits" associating with externalizing behavior (Krueger, Markon, Patrick, Benning, \& Kramer, 2007, p. 646). In a representative research effort that proved the existence of a general externalizing spectrum, factor analysis revealed that there are two largest factors: 1) drug-related problems; and 2) aggression-related problems (Krueger et al., 2007). Accordingly, it is expected that there are specific psychological predictors for drug offending.

\subsubsection{Psychological Risk Factors of Offending and Re-Offending}

Six psychological variables that were frequently found in the literature to be associated with adolescent offending and drug-involvement in delinquents are identified as risk factors for investigation. They are impulsiveness, aggressiveness (named as the "big two" in the ESC), empathy, social problem-solving, future time perspective and assertiveness. Research that had documented about their relationship with adolescent offending and re-offending was summarized below.

First, longitudinal studies on juvenile delinquency (e.g. Loeber, Stouthamer-Loeber, Farrington, \& Pardini, 1987-2001) revealed that early impulsiveness during childhood predicted later offending (Higgins, Kirchner, Ricketts, \& Marcum, 2013). It was identified as a risk factor of drug experimentation and drug use (De Wit, 2009); and could predict drug use severity and lifetime drug usage (Bernstein et al., 2015). Impulsiveness was found to predict recidivism among a group of juvenile probationers in Hong Kong (Chui \& Chan, 2012). Second, a lot of previous research had focused on childhood aggressiveness that predicted adolescent offending and drug abuse. Nevertheless, fewer studies had been conducted on whether adolescent aggressiveness predicted adult offending or drug abuse (Keltikangas-Jarvinen, 2008).

Empathy appeared to have a more complicated role in predicting offending behavior than the "big two". It is a central component of the concept of psychopathy that embraces traits lining to criminal behavior (Hare, 1993). Its linkage with higher recidivism among delinquents had been documented (Bock \& Hosser, 2013). It was positively associated with drug refusal efficacy (Nguyen, Clark, \& Belgrave, 2011). There is evidence that there are subtypes of conduct-disordered adolescents with different extents of deficits in empathy (or callous-unemotional traits) (Anastassiou-Hadjicharalambous \& Warden, 2008). A meta-analysis demonstrated that cognitive empathy was more strongly associated with offending than affective empathy (Van Langen, Wissink, Van Vugt, Van de Stouve, \& Stams, 2014). It replicated findings in an earlier meta-analysis conducted by Jolliffe and Farrington (2004), who suggested that longitudinal designs should be used to inquire into the relationship between empathy and offending. The present study was such an attempt. 
Social problem-solving (SPS) was another positive attribute that constitutes risk for later offending when it was in deficit. Ineffective SPS was found to be associated with interpersonal difficulties, behavioral problems and psychological maladjustment in the West and in Hong Kong (Siu \& Shek 2005; McGuire, 2001). A study conducted by Zamble and Quinsey (1997) was frequently quoted as they had specified the role of SPS in the recidivism process. They interviewed serious offenders and found that re-offences were preceded by difficulties in coping and poor self-management, and characterized by a lack of a positive problem-oriented approach that allowed problems to accumulate to unbearable levels until they experienced a "breakdown". Consistently, a recent review of 30 years of empirical evidence revealed that impaired SPS accompanied antisocial personality disorder and substance dependence (Thoma, Friedmann, \& Suchan, 2013).

Despite having been discussed less widely in risk factor research, the fifth factor, future time perspective (FTP), was found to be associated with antisocial behavior and recidivism among youngsters (Boyd \& Zimbardo, 2005; Carvalho, 2015). A recent meta-analysis showed that individuals with higher FTP were less likely to engage in drug use and risk-taking (Kooij, Kanfer, Betts, \& Rudolph, 2018). The last one, assertiveness, was the least understood. It was believed that some offences occurred because offenders could not deal effectively with anger or other negative emotions in assertive ways; and in particular drug-abusing offenders tended to have discomfort and deficiencies in assertive behavior in high-risk situations of relapse and thus easily slip to drug use (Vojudi, Otared, \& Poursharifi, 2014). Research in the 1980s had indicated that higher assertiveness was desirable in reducing likelihood of antisocial behavior and recidivism in particular to sexual offences (Segal \& Marshall, 1985). Although recent research gave contradictory results that assertiveness was associated with greater criminal tendency (Salekin, Debus, \& Barker, 2010), assertiveness training was included in many intervention programs for offenders and drug abusers in the West and in Hong Kong (Ainsworth, 2000; Queensland Government, 2013; HKCS, 2017).

\subsection{The Present Research}

The purpose of the present research was to identify specific psychological risk factors (if any) for drug offending that was seldom studied as a type of specific offending in prior risk factor research. To attain this purpose, a longitudinal post-hoc design, which could rectify limitations of prior cohort or cross-sectional research designs with which causal inferences could hardly be made, was applied on analysis of a young offender sample to differentiate recidivists from desistors; and prospective drug offenders from non-drug offenders with six important psychological risk factors. Apart from its practical implications on future development of risk assessment tool and focus of intervention targets in prevention of recidivism of offenders, it was hoped that results of the present research would shed light on applicability of two important and relevant theoretical paradigms.

According to the DST, a combination of psychological risk factors constitutes a general vulnerability to offending and drug abuse. However, the DST has been developed and validated in the Western cultural context, and its generalizability to other cultural contexts may be questionable. Therefore, we first investigated the association between the psychological risk factors and general recidivism to support the application of the DST on offenders in Hong Kong, which is a unique society of the blending of Chinese and Western cultures. General recidivism referred to re-offending of any types of crime after release from young offender institutions. It was used to represent a general inclination or vulnerability to revert to law-violation or deviant behaviors despite prior incarceration experience. Next, as the relationship of the psychological factors with drug offending may not be the same as those commonly shared among general offenders or recidivists, this research attempted to test out whether the two independent factors identified in the ESC, namely "drug-related" and "aggression-related" factors, would also be found in an offending population in Hong Kong. As the DST postulates, extreme scores on specific risk factors may account for the etiology of drug offending. This logic was applied in the process of identification of specific risk factors for drug offending in the present research.

\section{Method}

\subsection{Participants}

This study made use of a sample of incarcerated young offenders $(n=201,187$ males) who had initially been assessed in correctional institutions in Hong Kong in 2004, and were followed 11 years later in 2015. There are four different correctional programs in Hong Kong, namely the Rehabilitation Centre, Detention Centre, Training Centre, and Young Prisoner. All participants were selected through a stratified random sampling procedure, with their registered numbers in the HKCS rolled out from a computer program which ensured that the proportions of participants from each gender and correctional program were equal to those in the total population on a snapshot, i.e. a randomly selected date of reference (03.01.2004). In the stratification process, 
each correctional program was a relatively homogenous sub-group in terms of background characteristics, including demographics, criminal history, and offence severity. The sample was believed to be representative of the then young offender population in correctional institutions in Hong Kong.

The participants were 14 to 22 years old, with a mean age of 17.8 years ( $S D=1.62$ years). All the participants spoke Cantonese and read the traditional Chinese texts as their primary language. Prior to assessment, all participants consented to provide their information to the use of their information anonymously for research purposes. The data collection was approved by the ethics committee of the department given that the study would do no harm to the offenders and their welfare and rights would not be affected by their involvement in the study. Participants were fully briefed about the purpose of the study and the process of data collection.

\subsection{Measures}

\subsubsection{Impulsiveness}

The Impulsiveness subscale (I-7) of the Impulsiveness Questionnaire ( $7^{\text {th }}$ Version) (Eysenck, Pearson, Easting, \& Allsopp, 1985) assesses one of the three constructs, impulsiveness, included in the original Questionnaire. Support for its psychometric properties in cross-cultural studies was also demonstrated (Russo, Leone, \& De Pascalis, 2011). In this sample, the internal consistency was .72, which indicated good reliability. The two-week stability correlation was .81 (Pearson $r$ ) and .80 (ICC), suggesting good test-retest reliability.

\subsubsection{Aggressiveness}

The Aggression Questionnaire (AQ; Buss \& Perry, 1992) measures four aspects of aggressiveness, namely physical aggressiveness, verbal aggressiveness, anger and hostility. Stability over time and validity was shown by the test authors (Buss \& Perry, 1992). In this sample, the internal consistency of the AQ was .86, which indicated excellent reliability. The two-week stability correlation coefficient was .88 (for both Pearson $r$ and $I C C)$, which indicated good test-retest reliability.

\subsubsection{Empathy}

The Empathic Concern and Perspective Taking subscales (IRI-EP) of the Interpersonal Reactivity Index (IRI; Davis, 1980; 1983) were selected after careful review of previous research suggesting that they were positively correlated and predictive of later offending (Davis, 1980, 1983; De Corte, Buysse, Verhofstadt, Roeyers, Ponnet, \& Davis, 2007; Burke, 2001; HKCS, 2009). Reliability and validity of the IRI were shown in cross-cultural studies (Huang, Li, Sun, Chen, \& Davis, 2012). In this sample, the internal consistency ranged from .73 to .78, indicating good reliability. The test-retest reliability ranged from .72 to .77 for Pearson $r$ and from .71 to .76 for $I C C$, which were within the acceptable range.

\subsubsection{Social Problem Solving}

The Social Problem Solving Inventory (SPSI, D'Zurilla, \& Nezu, 1992) consists of two major subscales, namely Problem Orientation and Problem Solving Skills. The test authors have shown excellent internal consistency for SPSI, with alphas of .94 and three-week test-retest correlations of .87 (D'Zurilla \& Nezu, 1992). In this sample, the internal consistency of the SPSI was .93 , which indicated excellent reliability. The test-retest reliability was .91 (Pearson $r$ ) and .90 (ICC), which indicated high reliability.

\subsubsection{Future Time Perspective}

The future subscale is one of the five dimensions of time perspectives, namely past positive, past negative, present hedonistic, present fatalistic, and future, measured by the Zimbardo Time Perspective Inventory (ZTPI, Zimbardo \& Boyd, 1999). In an integrated research on the structural equivalence of the ZTPI across 26 samples from 24 countries $(N=12,200)$, the ZTPI was proven to be a valid and reliable index of individual differences in time perspectives (Sircova et al., 2014). In this sample, the internal consistency of the future subscale was .72, which indicated good reliability. The two-week stability correlation coefficient was .81 (for both Pearson $r$ and $I C C$ ), suggesting good test-retest reliability.

\subsubsection{Assertiveness}

The Simple Rathus Assertiveness Scale (SRAS; McCormick, 1984) is a parallel form of the Rathus Assertiveness Schedule (RAS; Rathus, 1973), which has established construct validity and an internal consistency of coefficient alpha equal to .90 . Evidence of cross-cultural reliability and validity was shown (e.g. Suzuki, Kanoya, Katsuki, \& Sato, 2007). The SRAS, which was designed for those with low educational attainment, correlates .94 with the original RAS (McCormick, 1984). In this sample, the internal consistency of SRAS was .70, which indicated good reliability. The test-retest reliability was .71 (for both Pearson $r$ and ICC), suggesting acceptable reliability. 


\subsubsection{Social Desirability}

It was commonly believed that self-report measures could be biased by basic human tendency to present oneself in the best possible light for ego defensive or impression management reasons (Fischer \& Fick, 1993). One of the techniques commonly used by researchers and also employed in this study to mitigate that bias was to include an independent measure on social desirability. The Marlowe-Crowne Social Desirability Scale (MCSDS, Crowne, \& Marlowe, 1960) was one of the most widely used measures for social desirability response style, and its psychometric properties were evaluated in numerous studies (Ventimiglia \& MacDonald, 2012). The short form of MCSDS (Fischer \& Fick, 1993) consisting of 13 items was employed in this study. This measure was used as a covariate to be controlled for, such that any relationship identified between the variables and the outcome would not be accountable for by response bias. Reliability coefficients ranged from .59 to .75 (Vésteinsdóttir, Reips, Joinson, \& Thorsdottir, 2015). In this sample, the internal consistency was .74, which indicated good reliability. The test-retest reliability was .73 (Pearson $r$ ) and $.72(I C C)$, which was within the acceptable range.

\subsection{Procedures}

The seven psychological measures, six on psychological risk factors and one on social desirability, were translated from English to traditional Chinese by a team of clinical psychologists working in the local correctional setting in 2002. The Chinese versions were translated back into English by a professional translator who had no knowledge of the original versions. The team of clinical psychologists then amended the wording of the traditional Chinese versions to reconcile it with the original English version. The final versions of the measures were administered to the participants in 2004 (Time 1) by specially trained correctional officers of the HKCS.

The dependent variables (DVs) were post-release outcomes retrieved from the official offender database of the HKCS in 2015 (Time 2). There were three DVs. The first one was Recidivism. It was a dichotomous and categorical variable consisting of two levels - Recidivist and Desistor. A Recidivist was defined as a previously incarcerated adolescent who had at least one re-conviction of a new offence causing re-incarceration after release. A Desistor was one who had not been re-convicted. The second and the third DVs applied only to the Recidivists. The second DV was future Drug Offending. It was also a dichotomous and categorical variable consisting of two levels- Drug offender (DO) and non-Drug offender (nDO). A DO was defined as a Recidivist who had committed one or more drug offence(s) causing re-incarceration after release. An nDO was a Recidivist who had committed any other offence(s) after release. The third DV was Future Crime-severity, which was operationally defined as: (a) Number of Re-convictions (NoRec); and (b) Total Re-sentence Length (ToRes).

\subsection{Data Analytic Strategy}

There were controversies in the research field against the human tendency of dichotomizing results as "significant" and "non-significant" with a number (i.e. $p<0.05$ ) (Fisher, 1935), which was not intended to be used as it was in contemporary research (Wasserstein, Schirm, \& Lazar, 2019). Recent debates had called "for an end to hyped claims" pertinent to statistical significance (Amrhein, Trafimow, \& Greenland, 2019). Researchers were advised to seek to analyze data in multiple ways to see whether different analyses converge on the same answer (Silberzahn \& Uhlmann, 2015). Attempting to address these controversies, the author of this research had employed two statistical tools for each variable inquiry; whereas a slight extension beyond the conventional statistical level of $p<0.05$ was adopted, with cautious consideration of all parameters that were highly suggestive of association among the variables.

The Statistical Package for Social Sciences version 19.0 (IBM Corporation, Armonk, NY, USA) was used. One-way Analysis of Covariance (ANCOVA) with planned orthogonal contrasts was conducted to compare the psychological risk factors of three distinct groups: 1) Desistors, 2) Recidivist-DO and 3) Recidivist-nDO. Contrast 1 was a comparison of the Desistors with the Recidivists. Contrast 2 was a comparison of the DO with the $\mathrm{nDO}$. To rule out the possibilities that any difference found might be due to effects of some major extraneous variables, three covariates including age of assessment, educational level and social desirability represented by MCSDS were controlled for. A second statistical tool namely hierarchical discriminant function analysis (DFA) was conducted to differentiate the Desistors from the Recidivists and the DO from the nDO. The logic of use of differentiation was in line with the DST suggesting that it is a promising tool for identifying etiology and assessing risk for future offending. The same three covariates were entered as a block at the first stage, followed by the six IVs that were entered simultaneously. Future Crime-severity represented by two indicators, number of re-convictions (NoRec) and total re-sentence length (ToRes), were analyzed with correlation and hierarchical linear regression analysis (HLRA). All six IVs were included in the HLRA regardless of whether a variable 
would have manifested any relationship with the DVs in the correlation analysis, with an aim to test out whether the results of correlation would change with variation in the context of variables included in an HLRA, which was the case commonly found in statistical analysis (Zou, Tuncali, \& Silverman, 2003). The same three covariates were controlled for in the HLRA.

\section{Results}

\subsection{Descriptive Statistics}

Among the 201 participants, 97 (48.3\%) were Recidivists and among the Recidivists, 47 (48.5\%) were DO. Table 1 showed the descriptive statistics of the scores on the six IVs among the Desistors, the Recidivist-DO and Recidivist-nDO after adjusting for three covariates.

Table 1. Descriptive Statistics of Psychological Risk Factors in Desistors, Recidivist-Drug Offenders and Recidivist-non-Drug Offenders

\begin{tabular}{lllllll}
\hline & Desistors & \multicolumn{3}{l}{ Recidivist-DO } & \multicolumn{2}{l}{ Recidivist-nDO } \\
\hline I-7 & Adjusted $M$ (Adjusted SD) & $n$ & Adjusted $M$ (Adjusted SD) & $n$ & Adjusted M (Adjusted SD) & $n$ \\
AQ & $9.98(3.88)$ & 95 & $10.78(3.39)$ & 45 & $9.14(3.69)$ & 50 \\
IRI-EP & $32.92(7.38)$ & 100 & $89.16(13.68)$ & 44 & $92.56(14.41)$ & 50 \\
SPSI & $147.82(33.54)$ & 101 & $30.30(7.83)$ & 46 & $31.04(7.07)$ & 50 \\
FTP & $3.29(.43)$ & 99 & $140.93(26.04)$ & 45 & $150.10(27.10)$ & 50 \\
SRAS & $93.82(13.55)$ & 100 & $3.10(.48)$ & 45 & $3.15(.45)$ & 50 \\
\hline
\end{tabular}

3.2 Comparing Recidivists with Desistors and Drug Offenders with Non-Drug Offenders

One-way ANCOVA with planned orthogonal contrasts was conducted to compare the Desistors with the Recidivists, and the DO with the $\mathrm{nDO}$ on the six IVs. Table 2 showed the results. Contrast 1 was a comparison of the Desistors with the Recidivists, and Contrast 2 was a comparison between the $\mathrm{DO}$ and the $\mathrm{nDO}$.

Table 2. Results of One-way ANCOVA with Planned Orthogonal Contrasts of Psychological Risk Factors by Recidivism (Contrast 1) and Drug Offending (Contrast 2)

\begin{tabular}{llllll}
\hline & Contrast & Value of Contrast & $S E$ & $t$ & $p$ \\
\hline I-7 & 1 & -.59 & .60 & -.97 & .332 \\
\multirow{2}{*}{ AQ } & 2 & -1.66 & .67 & $-2.48 *$ & .014 \\
& 1 & -.60 & 2.35 & -.25 & .800 \\
IRI-EP & 2 & 2.15 & 2.64 & .81 & .417 \\
& 1 & 2.32 & 1.26 & $1.84 \#$ & .067 \\
SPSI & 1 & .86 & 1.43 & .60 & .546 \\
& 2 & 5.76 & 4.99 & 1.16 & .250 \\
FTP & 1 & 9.65 & 5.63 & $1.71 \#$ & .088 \\
& 2 & .17 & .08 & $2.19 *$ & .030 \\
SRAS & 1 & .06 & .09 & .70 & .488 \\
& 2 & -4.06 & 2.33 & $-1.74 \#$ & .084 \\
& 1 & 1.03 & 2.64 & .39 & .696
\end{tabular}

$$
* p<.05 \quad \# p<.1
$$

Contrast 1 revealed that the Recidivists had scored significantly lower in FTP (Adjusted Means (SD) (DO \& $\mathrm{nDO})=3.10(.48) \& 3.15(.45))$ than the Desistors (Adjusted Mean $(S D)=3.29(.43))($ Beta $=.17, S E=.08, t=$ $2.19, p=.030)$. The mean IRI-EP of the Recidivists (Adjusted Means (SD) (DO \& nDO) $=30.30(7.83) \& 31.04$ (7.07)) was lower than that of the Desistors (Adjusted Mean $(S D)=32.92$ (7.38)), which just failed to reach conventional statistical significance $($ Beta $=2.32, S E=1.26, t=1.84, p=.067)$. The Recidivists had scored higher on SRAS (Adjusted Means (SD) (DO \& nDO) $=97.94$ (13.55) \& 99.56 (12.09) than the Desistors $($ Adjusted Mean $(13.55)=93.82)($ Beta $=-4.06, S E=2.33, t=-1.74, p=.084)$, which was approaching 
conventional statistical significance.

Contrast 2 revealed that the DO had scored significantly higher on I-7 (Adjusted Mean $(S D)=10.78(3.39)$ ) than the $\mathrm{nDO}$ (Adjusted Mean $(S D)=9.14(3.69))($ Beta $=-1.66, S E=.67, t=-2.18, p=.014)$. The difference in SPSI between the DO (Adjusted Mean $(S D)=140.93(26.04)$ ) and the $\mathrm{nDO}$ (Adjusted Mean $(S D)=150.10(27.10)$ ) was approaching conventional statistical significance (Beta $=9.65, S E=5.63, t=1.71, p=.088)$.

\subsection{Differentiation of Recidivists from Desistors}

In order to examine group differentiation by linear combination of IVs, hierarchical DFA was used to conduct a multivariate analysis of variance test to see whether the Recidivists and the Desistors would differ significantly in the six IVs. The three covariates, age, educational level, and social desirability, were entered in the first stage, followed by the six IVs as a group. The cumulative impact of adding a variable group to each subsequent analysis was assessed and summarized in Table 3, which showed that the amount of variance accounted for grew from $5.2 \%$ to $11.1 \%$ after the six IVs had been added to the analysis. The inclusion of the two variable groups resulted in two significant discriminant functions.

Table 3. Differentiation of Recidivists from Desistors - Cumulative Hierarchical Discriminant Function Information

\begin{tabular}{lllll}
\hline Variable Group & $X^{2}$ & $d f$ & Significance & $\mathbb{R}^{2}$ \\
\hline Cov & 10.27 & 3 & .016 & $.052(5.2 \%)$ \\
Cov + 6 Risk Factors & 20.30 & 9 & .016 & $.111(11.1 \%)$ \\
\hline
\end{tabular}

Note. $\mathrm{Cov}=$ Covariates, including demographics and social desirability

The 6 Risk Factors include mean scores on all 6 psychological measures

As indicated in Table 4, a rise in the number of Recidivists (from 56.3\% to 69.2\%) was classified with the inclusion of the second group of IVs.

Table 4. Differentiation of Recidivists from Desistors - Cumulative Hierarchical Discriminant Function Classification Information

\begin{tabular}{llll}
\hline & \multicolumn{3}{l}{ Percent correctly classified } \\
\hline Variable Group & Desistors & Recidivists & Total \\
\hline Cov & $63.4 \%$ & $56.3 \%$ & $59.9 \%$ \\
Cov + 6 Risk Factors & $61.4 \%$ & $69.2 \%$ & $65.4 \%$ \\
\hline
\end{tabular}

Note: $\mathrm{Cov}=$ Covariates, including demographics and social desirability

The 6 Risk Factors include mean scores on all 6 psychological measures

For the full model including the two variable groups, the DFA accounted for $11.1 \%$ of the between groups variance (Wilks $\left.\lambda=.889, X^{2}(9)=20.30, p=.016\right)$ and correctly classified $65.4 \%$ of the cases $(69.2 \%$ of the Recidivists and $61.4 \%$ of the Desistors). A linear combination of the variables, including three covariates and six IVs, could discriminate the Recidivists from the Desistors with the below discriminant function:

Discriminant Function $=.67 * \mathrm{FTP}+.56 *$ Educational level $-.37 *$ SRAS $-.27 *$ SPSI $-.26 * \mathrm{AQ}+.14 * \mathrm{I}-7$ $+.11 *$ IRI-EP $+.09 *$ Age of Assessment - $.04 *$ MCSDS

The discriminant function indicated that FTP was the most important psychological factor in discrimination of the Desistors and the Recidivists.

\subsection{Differentiation of Drug Offenders from Non-Drug Offenders}

Hierarchical DFA was also conducted to see whether the DO and the $\mathrm{nDO}$ would differ significantly in the six IVs. The three covariates were entered in the first stage, followed by the six IVs as a group. The two variables groups resulted in a non-significant discriminant function, Wilks $\lambda=.864, X^{2}(9)=12.32, p=.196(n s)$. As I-7 and SPSI were found to differ between the DO and the $\mathrm{nDO}$ in the ANCOVA with planned orthogonal analysis, a backward elimination procedure was taken to remove irrelevant variables in the DFA. Results showed that three of the six IVs, I-7, AQ and SPSI, contributed to a statistically significant discriminant function $(p=.047)$. The cumulative impact of adding each variable group to the DFA was summarized in Table 5, which showed that the amount of variance accounted for grew from $4.1 \%$ to $13.6 \%$ after the three IVs had been added to the analysis. 
Table 5. Differentiation of DO from nDO - Cumulative Hierarchical Discriminant Function Information

\begin{tabular}{lllll}
\hline Variable Group & $x^{2}$ & $d f$ & Significance & $R^{2}$ \\
\hline Cov & 3.91 & 3 & $.272(n s)$ & $.041(4.1 \%)$ \\
Cov + 3 Risk Factors & 12.73 & 6 & .047 & $.136(13.6 \%)$ \\
\hline
\end{tabular}

Note. $\mathrm{Cov}=$ Covariates, including Demographics and Social Desirability

The 3 Risk Factors include mean scores on 3 measures: I-7, AQ and SPSI.

As indicated in Table 6, a rise in the number of DO (from 54.3\% to 59.5\%) was classified with the inclusion of the three IVs.

Table 6. Differentiation of DO from nDO - Cumulative Hierarchical Discriminant Function Classification Information

\begin{tabular}{llll}
\hline \multirow{2}{*}{ Variable Group } & \multicolumn{3}{l}{ Percent correctly classified } \\
\cline { 2 - 4 } & $\mathrm{nDO}$ & $\mathrm{DO}$ & Total \\
\hline Cov & $68.0 \%$ & $54.3 \%$ & $59.9 \%$ \\
Cov +3 Risk Factors & $74.0 \%$ & $59.5 \%$ & $67.4 \%$ \\
\hline
\end{tabular}

Note. $\mathrm{Cov}=$ Covariates, including demographics and social desirability

The 3 Risk Factors include mean scores on 3 measures: I-7, AQ and SPSI

For the full model including the two variable groups, the DFA accounted for $13.6 \%$ of the between groups variance (Wilks $\left.\lambda=.864, X^{2}(6)=12.73, p=.047\right)$, and correctly classified $67.4 \%$ of the cases $(59.5 \%$ of the DO and $74 \%$ of the $\mathrm{nDO})$. A linear combination of the six IVs could discriminate the DO from the $\mathrm{nDO}$ with the below discriminant function:

Discriminant Function $=.91 * \mathrm{I}-7-.48 * \mathrm{AQ}+.44 * \mathrm{MCSDS}-.38 *$ Age of Assessment $-.21 *$ SPSI $+.15 *$ Educational Level

The discriminant function showed that I-7 was the most important IV in the discrimination of DO from $\mathrm{nDO}$.

\subsection{Predicting Future Crime-Severity of Drug Offenders}

Correlation and HLRA were conducted to examine the relationship between the IVs and the two indicators of Future Crime-severity: Number of Re-convictions (NoRec) and Total Re-sentence Length (ToRes). All IVs were included in the HLRA. The three covariates were entered in the first stage, followed by the six IVs as a group. Table 7 summarized the results of correlation and HLRA.

Table 7. Correlation and MLRA of Psychological Risk Factors in Predicting Number of Re-convictions in DO

\begin{tabular}{llllllll}
\hline Variables & Correlation with No. of Re-convictions & \multicolumn{7}{l}{ Multiple Linear Regression Analysis } & \\
\cline { 4 - 7 } & $r$ & $B$ & $S E B$ & $\beta$ & $p$ & Adjusted $\mathbb{R}^{2}$ (Sig.) \\
\hline Step 1 & & & & & & \\
Age & & -.02 & .18 & -.02 & .912 & .025 \\
Edu & & .59 & .31 & .321 & .065 & $(p=.270)$ \\
MCSD & & .03 & .13 & .033 & .847 & $($ ns) \\
Step 2 & & & & & & \\
Age & & .09 & .19 & .08 & .088 & $.215 *$ \\
Edu & & .59 & .31 & .32 & .59 & $(p=.041)$ \\
MCSD & & .27 & .15 & .34 & .270 & \\
SPSI & $-.43 *$ & -.05 & .01 & $-.75 * *$ & .001 & \\
AQ & .12 & .03 & .02 & .24 & .131 & \\
SRAS & $-.35 *$ & .03 & .02 & .22 & .222 & \\
I-7 & .21 & -.08 & .09 & -.17 & .350 & \\
IRI-EP & -.19 & -.03 & .04 & -.12 & .557 & \\
FTP & -.10 & .42 & .77 & .12 & .590 & \\
\hline
\end{tabular}

$* p<.05$ (two-tailed significance) $\quad * * p<.01$ (two-tailed significance)

Note: Age $=$ Age of Assessment

$\mathrm{Edu}=$ Educational Level 
Correlation revealed that SPSI $(r=-.43, p=.004)$ and SRAS $(r=-.35, p=.017)$ were significant negative correlates of NoRec among the DO. Table 7 showed that at Step 1, the covariates were not significant in contributing to the model. At Step 2, introducing the six IVs explained an additional $19 \%$ of variation in NoRec. Altogether the two groups accounted for $21.5 \%$ of the adjusted variance. The full regression model was significant (Adjusted $\mathbb{R}^{2}=.215, p=.041$ ). SPSI was found to be the most important predictor $(\beta=-.75, p$ $=.001)$. Besides, correlation revealed that SPSI was also a significant negative correlate with ToRes $(r=-.45, p$ $=.002)$ in the DO, whereas I-7 was a positive correlate close to conventional statistical significance $(r=.24, p$ $=.071)$. HLRA revealed that the prediction model was not significant, and none of the six IVs was significant. In sum, in the DO, SPSI was a negative correlate with both indicators of Future Crime-severity and a significant predictor in the regression equation for NoRec. SRAS was negatively correlated with NoRec and I-7 was positively correlated with ToRes.

\subsection{Predicting Future Crime-Severity of Non-Drug Offenders}

Although the present study had its major focus on drug offending, corresponding statistical analyses had been conducted on the $\mathrm{nDO}$ so that a contrast could be made with the results pertinent to the DO. Table 8 summarized the results of correlation and HLRA predicting NoRec in the $\mathrm{nDO}$ by the six IVs. Correlation revealed that IRI-EP was a significant negative correlate $(r=-.29, p=.041)$ of NoRec. At Step 1 of the HLRA, the three covariates were non-significant in contributing to the model. At Step 2, the two groups accounted for $9.2 \%$ of the variance. The full regression model just failed to reach conventional statistical significance (Adjusted $\mathbb{R}^{2}=.092$, $p=.063)$. IRI-EP was the only significant predictor in the equation $(p=.003)$. In sum, IRI-EP was the sole predictor for NoRec among the $\mathrm{nDO}$ in both correlation and regression analyses.

Table 8. Correlation and MLRA of Psychological Risk Factors in Predicting Number of Re-convictions in $\mathrm{nDO}$

\begin{tabular}{|c|c|c|c|c|c|c|}
\hline \multirow[b]{2}{*}{ Variables } & \multirow{2}{*}{$\begin{array}{c}\text { Correlation with No. of } \\
\text { Reconvictions } \\
r\end{array}$} & \multicolumn{5}{|c|}{ Multiple Linear Regression Analysis } \\
\hline & & $B$ & $S E B$ & $\beta$ & $p$ & $\begin{array}{l}\text { Adjusted } \\
R^{2} \text { (Sig.) }\end{array}$ \\
\hline \multicolumn{7}{|l|}{ Step 1} \\
\hline Age & & -.05 & .09 & -.09 & .574 & -.054 \\
\hline Edu & & -.04 & .12 & -.06 & .723 & $(p=.907)$ \\
\hline MCSD & & -.01 & .05 & -.03 & .832 & $(n s)$ \\
\hline \multicolumn{7}{|l|}{ Step 2} \\
\hline Age & & .08 & .09 & .14 & .397 & .092 \\
\hline Edu & & -.05 & .12 & -.06 & .694 & $(p=.063)$ \\
\hline MCSD & & -.08 & .07 & -.22 & .290 & \\
\hline IRI-EP & $-.29 *$ & -.07 & .02 & $-.55 * *$ & .003 & \\
\hline FTP & -.10 & 1.35 & .48 & .42 & .118 & \\
\hline $\mathrm{AQ}$ & -.07 & -.02 & .01 & -.38 & .132 & \\
\hline SPSI & -.06 & -.01 & .01 & -.31 & .159 & \\
\hline SRAS & .06 & .00 & .01 & .04 & .794 & \\
\hline $\mathrm{I}-7$ & -.00 & -.00 & .05 & -.02 & .932 & \\
\hline$* p<.05$ & ailed significance) & $<.01$ & ailec & ificance) & & \\
\hline
\end{tabular}

Table 9 summarized the results for another indicator of Future Crime-severity: ToRes. Correlation revealed that IRI-EP was a significant negative correlate $(r=-.35, p=.014)$ of ToRes. At Step 1 , the covariates had not significantly contributed to the prediction model. At Step 2, introducing the six IVs explained an additional $23 \%$ of variation in the DV. The full hierarchical regression model of prediction yielded a statistically significant 
model (Adjusted $R^{2}=.220, p=.012$ ). Both indicators of Future Crime-severity gave convergent results unveiling the important role of IRI-EP in predicting Future Crime-severity in nDO.

Table 9. Correlation and MLRA of Psychological Risk Factors in Predicting Total Re-sentence Length in nDO

\begin{tabular}{|c|c|c|c|c|c|c|}
\hline \multirow[b]{2}{*}{ Variables } & \multirow{2}{*}{$\begin{array}{l}\text { Correlation with Total } \\
\text { Re-sentence Length } \\
r\end{array}$} & \multicolumn{5}{|c|}{ Multiple Linear Regression Analysis } \\
\hline & & $B$ & $S E B$ & $\beta$ & $p$ & $\begin{array}{l}\text { Adjusted } \\
\boldsymbol{R}^{2} \text { (sig.) }\end{array}$ \\
\hline \multicolumn{7}{|l|}{ Step 1} \\
\hline Age & & 1.62 & 2.33 & .10 & .489 & -.01 \\
\hline Edu & & -3.67 & 3.23 & -.17 & .261 & $(p=.482)$ \\
\hline MCSD & & -1.70 & 1.40 & -.18 & .233 & \\
\hline \multicolumn{7}{|l|}{ Step 2} \\
\hline Age & & 4.97 & 2.30 & $.32 *$ & .037 & .220 \\
\hline Edu & & -4.15 & 3.08 & -.19 & .186 & $(p=.012)$ \\
\hline MCSD & & -3.67 & 1.81 & $-.39 *$ & .049 & \\
\hline IRI-2sc & $-.35 *$ & -2.03 & .59 & $-.56 * *$ & .001 & \\
\hline FTP & -.06 & 30.33 & 11.91 & .40 & .109 & \\
\hline AQ & -.11 & -.72 & .34 & -.37 & .124 & \\
\hline SRAS & .18 & .47 & .28 & .34 & .133 & \\
\hline SPSI & -.11 & -.29 & .19 & -.20 & .145 & \\
\hline $\mathrm{I}-7$ & -.05 & -.01 & 1.26 & -.00 & .996 & \\
\hline
\end{tabular}

$* p<.05$ (two-tailed significance) $\quad * * p<.01$ (two-tailed significance)

Note: Age $=$ Age of Assessment

$\mathrm{Edu}=$ Educational level

\section{Discussion}

The purpose of the present research was to identify psychological risk factors for drug offending within the context of adolescent offending and re-offending. A longitudinal post-hoc design was applied on analysis of a young offender sample to differentiate recidivists from desistors; and prospective drug offenders from non-drug offenders with six important psychological risk factors. Subgroups of participants spanning 11 years from adolescence through adulthood, based on official criminal record of 201 ex-young-offenders, were identified. About half of them were classified as recidivists, and half of the recidivists were classified as drug offenders. Results of statistical analysis revealed that general recidivism and drug offending were predicted by different risk factors in different manners. The results had implications on future psychological intervention on young offenders in prevention of general recidivism and future drug offending.

Consistent with the DST of crime, which suggests that a general vulnerability to offending is formed by a combination of many individual risk factors; half of the psychological risk factors under investigation were predictive of recidivism of young offenders in Hong Kong. The recidivists had lower empathy and future time perspective, and the undesirable role of assertiveness concurred with recent Western research (Salekin et al., 2010). The importance of empathy in predicting recidivism suggests that the pathway from adolescent to persistent offending can be reshaped through empathy enhancement, especially for those who were not prone to use illicit drugs in their drug-abuse attitudes and psychological characteristics. Besides, future time perspective deserves more attention in intervention on young offenders than it had received in the literature.

Consistent with the ESC, drug offending among local young offenders could be predicted by a specific set of psychological risk factors: impulsiveness, and low social problem solving and assertiveness. This implies that etiology of drug offending may be different from general offending. Among the three factors, impulsiveness and problem solving also predicted future crime-severity among the drug offenders, suggesting that these two variables are highly relevant to drug involvement as the youths proceeded into adulthood. As one of the "big 
two" risk factors in the ESC, impulsiveness had exerted powerful influence on future drug offending. It was confirmative of the postulation that the impulsive system of the young brains would be sensitized towards drug and pertinent cues with their continual drug use; and long-term effects are further impairments of the ability to inhibit and regulate impulsive action tendencies associating with further offending; until they get trapped in a vicious cycle of persistent drug abuse and offending that they cannot exit (MacKillop, Amlung, Few, Ray, Sweet, \& Munafo, 2011). In our sample, impulsiveness that also predicted total re-sentence length in drug offenders might be the reason behind the hasty decisions and higher risk the long-sentence offenders had taken in the process of their decision to commit crimes of more serious consequences, such as those involving a large quantity of drugs. Research in the recent decade has shown that impulsiveness in offenders is dynamic and can be reduced by various modes of systematic psychological treatment, including cognitive-behavioral interventions and mindfulness based programs (Leonard et al., 2013). A major implication of the present result is that impulsiveness can be placed on a higher treatment priority in intervention efforts aiming at reduction of future drug-involvement in young offenders.

As the second most important psychological factor of drug offending, social problem-solving was also found to have diverted local youngsters' path towards or against future drug offending and also determined the drug offenders' crime severity. The association can be attributed to the strong linkage between drug abuse and drug offending. Individuals with the deficits might lack the specific skills to identify or negotiate their way out of high-risk situations of drug abuse and offending until it was too late (Platt \& Husband, 1993). Besides, deficiencies in problem-solving also led to failures or unsatisfactory interpersonal outcomes that led to negative affective states and then to drug use (Marlatt \& Gordon, 1980). The negative affective states and acts of relapse to drug use might then produce a sense of total "giving up" in the individuals, who might soon opt to commit crimes in a state of little concern or contemplation about the consequences of offending (Marlatt, 1985). The implication to psychological intervention is that enhancing social problem-solving is a promising strategy to divert justice-involved youngsters away from later drug use and drug offending, especially as cognitive problem-solving interventions have been found to be particularly effective in the amelioration of problem and offending behaviors of youngsters (Black \& Blum, 2017).

It must be highlighted here that in this study, severity of future drug offending has been predicted by a greater number of psychological risk factors (i.e. impulsiveness, problem solving and assertiveness) than that for non-drug offending (i.e. empathy). It suggests that drug offenders may possess more vulnerability factors associating with their repeat offending; or in other words, possess more individual needs requiring attention and intervention than their non-drug offending counterparts in their rehabilitation.

Although the DST was found to be largely applicable to young offenders who grew up in Hong Kong, results of this study had not replicated Western research that demonstrated association of the "big two" (impulsiveness, aggressiveness) and social problem-solving with general recidivism. Besides, our result was contradictory to research evidence in the 1980s suggesting that assertiveness tended to be lower among recidivists. There was a likelihood that the cultural context of Hong Kong had exerted an influence on this result. It has been discussed that assertiveness is considered positive and desirable in Western societies but is sometimes regarded as negative or undesirable in Chinese societies (Liu, 2003). Nevertheless, it could not be ruled out that the discrepancy might also be related to a change in the triad subculture in Hong Kong from that in the 1980s, when assertiveness might be desirable in the process of resisting crime involvement; to the updated scene that higher assertiveness would be regarded as more desirable among the stronger or tougher "hard core" criminals, who usually had a higher tendency to re-offend (Salekin et al., 2010). Interestingly, consistent with the literature on drug abuse and relapse that had documented assertiveness as a highly relevant predictor, being more assertive was found to have helped drug offenders in our sample reduce post-release crime-severity, possibly through success in resisting involuntary engagement in crimes or drug-related activities (Ainsworth, 2000; Vojudi et al., 2014). Our results imply that drug offenders may be different from other offenders in a way that their repeat offending has been influenced to a less extent by the triad subculture and more by individual vulnerability in their path to re-offending. Just as future time perspective and empathy that have predicted general recidivism in this research, assertiveness is also worthy of more attention in future research and treatment on local young offenders. A further implication is that assertiveness training may be beneficial only to those who are more prone to drug-involvement as reflected in their drug abuse history and psychological characteristics.

In regard to the "big two" in the ESC, impulsiveness and aggressiveness, our results suggested that this liability dimension causing externalization in childhood may be important in predicting adolescent offending but not for their persistent offending in adulthood. One of the possible reasons is that young offenders generally grow out of impulsiveness and aggressiveness as they proceed from adolescence into adulthood (Higgins et al., 2013; 
Karriker-Jaffe, Foshee, Ennett, \& Suchindran, 2008), making the effects of the "big two" on recidivism in the age-range covered in this study less prominent than that in the range of childhood to adolescence as always covered in previous research (Farrington, 1992; Keltikangas-Jarvinen, 2008). In this light, our findings have filled the knowledge gap of how the "big two" risk factors of externalization impact on offending in adulthood. Last but not least, our results have confirmed the prediction of the ESC that aggression-related problems is a distinct factor which is independent of drug-related problems predictive of drug offending, and it has not exerted any observable effect on future drug offending.

\section{Summary}

The present research has confirmed that two important theoretical paradigms for offending and drug abuse, the DST and the ESC, are applicable to the young offender population in Hong Kong, although the cultural context and the age group may have compromised its compatibility with the corresponding phenomenon in the West. This research reveals that there are specific psychological risk factors predicting prospective drug offending among young offenders. There were two sets of factors with little overlap in predicting general recidivism and drug offending. Recidivism was predicted by low empathy (which was particularly relevant to non-drug offending), low future time perspective, and high assertiveness. In contrast, drug offending and its crime severity was predicted by high impulsiveness and social problem-solving deficits. Assertiveness was not favorable to general desistance but could lower the severity of future drug offending. Drug offenders might be less affected by external factors, such as triad subculture, and more affected by individual vulnerability factors in their repeat offending. They were found to possess more individual needs requiring attention and intervention in rehabilitation attempts.

\section{Limitations}

Owing to its longitudinal nature and lack of control over selection of independent variables, the present research had unavoidably missed some important factors previously found to be strongly associated with adolescent offending and re-offending. Examples were attitudinal variables and drug dependence. Social and criminal psychology research has consistently indicated that criminal attitude or thinking has an important role in association with criminal behavior (Walters, 2016; Banse, Koppehele-Gossel, Kistemaker, Werner, \& Schmidt, 2013). Drug dependence has also been investigated as a risk factor of offending (Van Der Put, Creemers, \& Hoeve, 2014). It is likely that some missing psychosocial variables will have significant interactions with the risk factors included this study. Without examination of these variables, how psychological risk factors might work together, for example, with some factors mediating or moderating others to produce certain effects, remained elusive. Future research should consider more sophisticated techniques, such as path analysis, to delineate the relationship among more risk factors and the mechanisms of how they would have contributed to drug offending when a more comprehensive set of predictors can be included.

\section{Conclusion}

The present research is one of the first attempts to identify psychological risk factors of future drug offending among adolescent offenders in an Asian society. The implications of existence of specific risk factors for drug offending is great both in theoretical and practical realms. To a lot of stakeholders' concern, future rehabilitation for young offenders can be steered towards the most relevant psychological risk factors. Efforts are worthy paying to reduce risk of later drug offending among justice-involved youths through targeting those specific factors. Besides, this research has proven that it is possible to study drug offending as a type of specific offending as other frequently investigated ones (such as sexual and violent offending), and it can be predicted as early as in adolescence. It is hoped that there will be similar research attempts in the future, such that evidence-informed risk assessment tools for drug offending can be developed and applied in early identification of and need-matching intervention for individuals at risk, for the ultimate objective to reduce future drug offending, which is difficult to desist from in a long run, among young offenders.

\section{References}

Ainsworth, P. B. (2000). Psychology and Crime. Longman.

Amrhein, V., Trafimow, D., \& Greenland, S. (2019). Inferential statistics as descriptive statistics: there is no replication crisis if we don't expect replication. The American Statistician, 73, 262-270. https://doi.org/10.1080/00031305.2018.1543137

Anastassiou-Hadjicharalambous, X., \& Warden, D. (2008). Cognitive and affective perspective-taking in conduct-disordered children high and low on callous-unemotional traits. Child and Adolescent Psychiatry and Mental Health, 2(16), 1-11. https://doi.org/10.1186/1753-2000-2-16 
Audit Commission of Hong Kong (2015). Rehabilitation services provided by the Correctional Services Department. Report on Audit Commission, 2015, Chapter 8: Correctional Services Department.

Banse, R., Koppehele-Gossel, J., Kistemaker, L. M., Werner, V. A., \& Schmidt, A. F. (2013). Pro-criminal attitudes, intervention, and recidivism. Aggression and Violent Behaviour, 18, 673-685. https://doi.org/10.1016/j.avb.2013.07.024

Belsky, J., \& Pluess, M. (2009). Beyond diathesis stress: Differential susceptibility to environmental influences. Psychological Bulletin, 135(6), 885-908. https://doi.org/10.1037/a0017376

Bernstein, M. H., McSheffrey, S. N., van den Berg, J. J., Vela, J. E., Stein, LAR, Roberts, M. B., Martin, R. A., \& Clarke, G. J. (2015). The association between impulsivity and alcohol/drug use among prison inmates. Addictive Behavior, 42, 140-143. https://doi.org/10.1016/j.addbeh.2014.11.016

Black, D. W., \& Blum, N. (2017). Systems training for emotion predictability and problem solving: The STEPPS treatment model for persons with borderline personality disorder. New York: Oxford University Press. https://doi.org/10.1093/med:psych/9780199384426.001.0001

Bock, E. M., \& Hosser, D. (2013). Empathy as a predictor of recidivism among young adult offenders. Psychology Crime and Law, 20(2), 1-15. https://doi.org/10.1080/1068316X.2012.749472

Boyd, J. N., \& Zimbardo, P. G. (2005). Time perspective, health and risk taking. In Strathman, A., \& Joireman, J. (Eds.), Understanding Behavior in the Context of Time. Theory, Research and Application. Mahwah, NJ: Erlbaum, 88-107.

Burke, D. M. (2001). Empathy in sexually offending and non-offending in adolescent males. Journal of Interpersonal Violence, 16, 222-233. https://doi.org/10.1177/088626001016003003

Buss, A. H., \& Perry, M. (1992). Aggression Questionnaire (AQ). Journal of Personality and Social Psychology, 63, 452-459. https://doi.org/10.1037/0022-3514.63.3.452

Carvalho, R. G. G. (2015). Future time perspective as a predictor of adolescents' adaptive behavior in school. School Psychology International, 36(5), 482-497. https://doi.org/10.1177/0143034315601167

Chui, W. H., \& Chan, H. C. O. (2012). Criminal Recidivism Among Hong Kong Male Juvenile Probationers. Journal of Child and Family Studies, 21, 857-868. https://doi.org/10.1007/s10826-011-9546-0

Crowne, D. P., \& Marlowe, D. (1960). A new scale of social desirability independent of psychopathology. Journal of Consulting Psychology, 24, 349-354. https://doi.org/10.1037/h0047358

D'Zurilla, T. J., \& Nezu, A. M. (1992). Development and preliminary evaluation of the Social Problem Solving Inventory (SPSI). Psychological Assessment: A Journal of Consulting and Clinical Psychology, 2(2), 156-163. https://doi.org/10.1037/1040-3590.2.2.156

Davis, M. H. (1980). A multidimensional approach to individual differences in empathy. JSAS Catalog of Selected Documents in Psychology, 10, 85.

Davis, M. H. (1983). Measuring individual differences in empathy: Evidence for a multidimensional approach. Journal of Personality and Social Psychology, 44, 113-126. https://doi.org/10.1037/0022-3514.44.1.113

De Corte, K., Buysse, A., Verhofstadt, L. L., Roeyers, H., Ponnet, K., \& Davis, M. H. (2007). Measuring empathic tendencies: reliability and validity of the Dutch version of the Interpersonal Reactivity Index. Psychologica Belgica, 47(4), 235-260. https://doi.org/10.5334/pb-47-4-235

De Wit, H. (2009). Impulsivity as a determinant and consequence of drug use: a review of underlying process. Addiction Biology, 14(1), 22-31. https://doi.org/10.1111/j.1369-1600.2008.00129.x

Eysenck, S. B. G., Pearson P. R., Easting G., \& Allsopp, J. F. (1985). Age norms for impulsiveness, venturesomeness and empathy in adults. Personality and Individual Differences, 6(5), 613-619. https://doi.org/10.1016/0191-8869(85)90011-X

Eysenck, H. J. (1987). Personality theory and the problem of criminality. In McGurk, B., Thornton, D. \& Williams., M. (Eds.), Applying Psychology to Imprisonment. London, HMSO, 30-46.

Farrington, D. P. (1992). Juvenile delinquency. In Coleman, J. C. (Eds.), The School Years (2nd ed.), London: Routledge, 123-163.

Fischer, D. G., \& Fick, C. (1993). Measuring social desirability: Short forms of the Marlowe-Crowne social desirability scale. Educational and Psychological Measurement, 53(2), 417-424. https://doi.org/10.1177/0013164493053002011 
Fisher, R. A. (1935). The Design of Experiments. Edinburgh, UK: Oliver \& Boyd.

Grant, J. E., \& Chamberlain, S. R. (2014). Impulsive action and impulsive choice across substance and behavioral addictions: Cause or consequence? Addictive Behaviors, 39(11), 1632-1639. https://doi.org/10.1016/j.addbeh.2014.04.022

Hare, R. D. (1993). Without Conscience: The Disturbing World of the Psychopaths among Us. New York, NY: The Guilford Press.

Higgins, G. E., Kirchner, E. E., Ricketts, M. L., \& Marcum, C. D. (2013). Impulsivity and Offending from Childhood to Young Adulthood in the United States: A Developmental Trajectory Analysis, International Journal of Criminal Justice Sciences (IJCJS). Official Journal of the South Asian Society of Criminology and Victimology, 8(2), 182-197.

HKCS. (2009). Empathy and Recidivism among Young Offenders - a Preliminary Study. An Internal Career Project conducted by the Working Group on Young Offender, Psychological Services Section 2, Hong Kong Correctional Services.

HKCS. (2017). Table of Treatment Manuals for Drug Abuse Treatment Centres. Working Group on Assessment and Treatment for Drug Abusers, Psychological Services Section 2, Hong Kong Correctional Services.

HKCS. (2018). Hong Kong Correctional Services Annual Review of 2018.

Huang, X. Z., Li, W. J., Sun, B. H., Chen, H., \& Davis, M. H. (2012). The validation of the Interpersonal Reactivity Index for Chinese teachers from primary and middle schools. Journal of Psychoeducational Assessment, 30(2), 194-204. https://doi.org/10.1177/0734282911410588

Jolliffe, D., \& Farrington, D. P. (2004). Empathy and offending: A systematic review and meta-analysis. Aggression and Violent Behavior, 9, 441-476. https://doi.org/10.1016/j.avb.2003.03.001

Karriker-Jaffe, K. J., Foshee, V. A., Ennett, S. T., \& Suchindran, C. (2008). The development of aggression during adolescence: Sex differences in trajectories of physical and social aggression among youth in rural areas. Journal of Abnormal and Child Psychology, 36(8), 1227-1236. https://doi.org/10.1007/s10802-008-9245-5

Keltikangas-Jarvinen, L. (2008). Social problem-solving and the development of aggression. In McMurran, M., \& McGuire, J. (Eds.), Social Problem Solving and Offending: Evidence, Evaluation and Evolution. Chichester, UK: John Wiley \& Sons Ltd., 31-50. https://doi.org/10.1002/9780470713488.ch2

Kooij, D. T. A. M., Kanfer, R. M., Betts, C., \& Rudolph, W. (2018). Future time perspective: a systematic review and meta-analysis. Journal of Applied Psychology, 103, 867-893. https://doi.org/10.1037/apl0000306

Krueger, R. F., Markon, K. E., Patrick, C. J., Benning, S. D., \& Kramer, M. D. (2007). Linking antisocial behavior, substance use, and personality: an integrative quantitative model of the adult externalizing spectrum. Journal of Abnormal Psychology, 116(4), 645-666. https://doi.org/10.1037/0021-843X.116.4.645

Leonard, N. R., Jha, A. P., Casarjian, B., Goolsarran, M., Garcia, C., Cleland, C. M., Gwadz, M. V., \& Massey, Z. (2013). Mindfulness training improves attentional task performance in incarcerated youth: a group randomized controlled intervention trial. Frontiers in Psychology, 4, 792-805. https://doi.org/10.3389/fpsyg.2013.00792

Leue, A., Brocke, B., \& Hoyer, J. (2008). Reinforcement sensitivity of sex offenders and non-offenders: An experimental and psychometric study of reinforcement sensitivity theory. British Journal of Psychology, 99, 361-378. https://doi.org/10.1348/000712607X228519

Liu, Q. X. (2003). Understanding Different Cultural Patterns or Orientations between East and West. Investigationes Linguisticae, vol. IX, Poznań.

Loeber, R., Stouthamer-Loeber, M., Farrington, D., \& Pardini, D. (1987-2001). Pittsburgh Youth Study Youngest Sample (1987-2001) [Pittsburgh, Pennsylvania]. ICPSR36453-v1. Arbor, A. (2016). MI: Inter-university Consortium for Political and Social Research [distributor].

MacKillop, J., Amlung, M. T., Few, L. R., Ray, L. A., Sweet, L. H., \& Munafo, M. R. (2011). Delayed reward discounting and addictive behaviour: a meta-analysis. Psychopharmacology, 216, 305-321. https://doi.org/10.1007/s00213-011-2229-0

Marlatt, G. A. (1985). Relapse prevention: Theoretical rationale and overview of model. In Marlatt, G. A., \& Gordon, J. R. (Eds.), Relapse Prevention. New York: Guilford Press, 3-67. 
Marlatt, G. A., \& Gordon, J. R. (1980). Determinants of relapse prevention: Implications for the maintenance of behavior change. In Davidson, P. O., \& Davidson, S. M. (Eds.), Behavioral Medicine: Changing Health Lifestyles. New York: Brunner/Mazel.

Marshall, W. L., Anderson, D., \& Fernandez, Y. M. (1999). Cognitive Behavioral Treatment of Sexual Offenders. Chichester, UK: Wiley.

McCormick, I. A. (1984). A simple version of the Rathus Assertiveness Schedule. Behavioral Assessment, 7 , 95-99. https://doi.org/10.1037/t03152-000

McGuire, J. (2001). What is problem-solving? A review of theory, research and applications. Criminal Behavior and Mental Health, 11, 210-235. https://doi.org/10.1002/cbm.397

Mulloy, R. (2015). The impact of empathy training on offender treatment. Forum on Corrections Research, 11(1). $\begin{array}{llll}\text { Correctional } & \text { Service } & \text { Canada. } & \text { Retrieved }\end{array}$ http://www.csc-scc.gc.ca/research/forum/e111/e111d-eng.shtml

National Drug Intelligence Center. (2011). National Drug Threat Assessment. U.S. Department of Justice. Retrieved from https://www.justice.gov/archive/ndic/pubs44/44849/44849p.pdf

Nguyen, A. B., Clark, T. T., \& Belgrave, F. C. (2011). Empathy and drug use behaviors among African-American adolescents. Journal of Drug Education, 41(3), 289-308. https://doi.org/10.2190/DE.41.3.d

Platt, J. J., \& Husband, S. D. (1993). An overview of problem-solving and social skills approaches in substance abuse treatment. Psychotherapy, 30, 276-283. https://doi.org/10.1037/0033-3204.30.2.276

Prichard, J., \& Payne, J. (2005). Key findings from the Drug Use Careers of Juvenile Offenders study. Trends and Issues in Crime and Criminal Justice. Australian Institute of Criminology. Australian Government.

Queensland Government. (2013). Induction Module 6: Relapse Prevention and Management. InSight: Alcohol and Other Drug Education and Training Unit, Metro North Mental Health - Alcohol and Drug Service, Brisbane Queensland.

Rathus, S. A. (1973). A 30-item schedule for assessing assertive behavior. Behavior Therapy, 4, 398-406. https://doi.org/10.1016/S0005-7894(73)80120-0

Russo, P. M., Leone, L., \& De Pascalis, V. (2011). Cross-cultural validity of the I7 impulsiveness-venturesomeness-empathy scales: evidence from the Italian I7. Comprehensive Psychiatry, 52(4), 446-452. https://doi.org/10.1016/j.comppsych.2010.07.008

Salekin, R., Debus, S., \& Barker, E. (2010). Adolescent Psychopathy and the Five Factor Model: Domain and Facet Analysis. Journal of Psychopathology and Behavioral Assessment, 32(4), 501-514. https://doi.org/10.1007/s10862-010-9192-7

Segal, Z. V., \& Marshall, W. L. (1985). Heterosexual social skills in a population of rapists and child molesters. Journal of Consulting and Clinical Psychology, 53(1), 55-63. https://doi.org/10.1037/0022-006X.53.1.55

Silberzahn, R., \& Uhlmann, E. L. (2015). Crowded research: many hands make tight work. Nature, 526, $189-191$. https://doi.org/10.1038/526189a

Sircova, A., Van De Vijver, F. J. R., Osin, E., Milfont, T. L, Fieulaine, N., Kislali-Erginbilgic, A., Zimbardo, P. G., Djarallah, S., Chorfi, M. S. et al. (2014). A global look at time: a 24-country study of the equivalence of the Zimbardo Time Perspective Inventory. SAGE Open, 4(1), 1-12. https://doi.org/10.1177/2158244013515686

Siu, A. M. H., \& Shek, D. T. L. (2005). Validation of the Interpersonal Reactivity Index in a Chinese context. Research on Social Work Practice, 15(2), 118-126. https://doi.org/10.1177/1049731504270384

Substance Abuse and Mental Health Services Administration. (2018). Key Substance Use and Mental Health Indicators in the United States: Results from the 2017 National Survey on Drug Use and Health.

Suzuki, E., Kanoya, Y., Katsuki, T., \& Sato, C. (2007). Verification of reliability and validity of a Japanese version of the Rathus Assertiveness Schedule. Journal of Nursing Management, 15(5), 530-537. https://doi.org/10.1111/j.1365-2834.2007.00691.x

Thoma, P., Friedmann, C., \& Suchan, B. (2013). Empathy and social problem solving in alcohol dependence, mood disorders and selected personality disorders. Neuroscience and Biobehavioral Reviews, 37(3), 448-470. https://doi.org/10.1016/j.neubiorev.2013.01.024

USLegal. (2019). Drug Offenses Law and Legal Definition. Retrieved from https://definitions.uslegal.com/d/drug-offenses/ 
Van Der Put, C. E., Creemers, H. E., \& Hoeve, M. (2014). Difference between juvenile offenders with and without substance use problems in the prevalence and impact of risk and protective factors for criminal recidivism. Drug and Alcohol Dependence, 134, 267-274. https://doi.org/10.1016/j.drugalcdep.2013.10.012

Van Langen, M. A. M., Wissink, I. B., Van Vugt, E. S., Van de Stouve, T., \& Stams, G. J. J. M. (2014). The relation between empathy and offending: a meta-analysis. Aggression and Violent Behavior, 19(2), 179-189. https://doi.org/10.1016/j.avb.2014.02.003

Ventimiglia, M., \& MacDonald, D. A. (2012). An examination of the factorial dimensionality of the Marlowe-Crowne social desirability scale. Personality and Individual Differences, 52, 487-491. https://doi.org/10.1016/j.paid.2011.11.016

Vésteinsdóttir, V., Reips, U., Joinson, A., \& Thorsdottir, F. (2015). Psychometric properties of measurements obtained with the Marlowe-Crowne Social Desirability Scale in an Icelandic probability based Internet sample. Computers in Human Behavior, 49, 608-614. https://doi.org/10.1016/j.chb.2015.03.044

Vojudi, B., Otared, N., \& Poursharifi, H. (2014). On the comparison of interpersonal sensitivity and assertiveness between drug-dependent and normal people. Research on Addiction Quarterly Journal of Drug Abuse, $8(31), 86-92$.

Walters, G. D. (2014). Crime and substance misuse in adjudicated youth: the worst of both ends. Law and Human Behavior, 38(2), 139-150. https://doi.org/10.1037/lhb0000050

Walters, G. D. (2015). The latent structure of criminal persistence: a taxometric analysis of offending behavior from late adolescence to early adulthood in adjudicated male delinquents. American Journal of Criminal Justice, 40, 542-559. https://doi.org/10.1007/s12103-014-9272-4

Walters, G. D. (2016). Crime continuity and psychological inertia: testingthe cognitive mediation and additive postulates with male adjudicated delinquents. Journal of Quantitative Criminology, 32, 237-252. https://doi.org/10.1007/s10940-015-9262-9

Wasserstein, R. L., Schirm, A. L., \& Lazar, N. A. (2019). Moving toward a world beyond "p< 0.05". The American Statistician, 73(1), 1-19. https://doi.org/10.1080/00031305.2019.1583913

World Health Organization. (2020). Management of substance abuse - Facts and figures. Retrieved from https://www.who.int/substance_abuse/facts/en/

Zamble, E., \& Quinsey, V. L. (1997). The Criminal Recidivism Process. Cambridge England; New York, NY, USA: Cambridge University Press. https://doi.org/10.1017/CBO9780511527579

Zimbardo, P. G., \& Boyd, J. N. (1999). Putting time in perspective: A valid, reliable individual-differences metric. Journal of Personality and Social Psychology, $77(6), \quad$ 1271-1288. https://doi.org/10.1037/0022-3514.77.6.1271

Zou, K. H., Tuncali, K., \& Silverman, S. G. (2003). Correlation and Simple Linear Regression. Radiology, 227, 617-628. https://doi.org/10.1148/radiol.2273011499

\section{Copyrights}

Copyright for this article is retained by the author(s), with first publication rights granted to the journal.

This is an open-access article distributed under the terms and conditions of the Creative Commons Attribution license (http://creativecommons.org/licenses/by/4.0/). 